\title{
Perceived Need for Psychosocial Support After Aortic Dissection: Cross-Sectional Survey
}

Gunther Meinlschmidt ${ }^{1,2,3}$, Prof Dr rer nat; Denis Berdajs ${ }^{4}$, Prof Dr med; Roger Moser-Starck ${ }^{1}$, Dr med; Alexander Frick $^{1}$, Dr med; Sebastian Gross ${ }^{1}$, MS; Ulrich Schurr ${ }^{4}$, Dr med; Friedrich S Eckstein ${ }^{4}$, Prof Dr med; Sabina Hunziker ${ }^{1,5}$, Prof Dr med; Rainer Schaefert ${ }^{1}$, Prof Dr med

\footnotetext{
${ }^{1}$ Department of Psychosomatic Medicine, Faculty of Medicine, University of Basel and University Hospital Basel, Basel, Switzerland

${ }^{2}$ Division of Clinical Psychology and Epidemiology, Department of Psychology, University of Basel, Basel, Switzerland

${ }^{3}$ Division of Clinical Psychology and Cognitive Behavioral Therapy, International Psychoanalytic University, Berlin, Germany

${ }^{4}$ Division of Cardiac Surgery, University Hospital Basel, Basel, Switzerland

${ }^{5}$ Division of Medical Communication, Department of Psychosomatic Medicine, University Hospital Basel, Basel, Switzerland
}

\section{Corresponding Author:}

Gunther Meinlschmidt, Prof Dr rer nat

Department of Psychosomatic Medicine

Faculty of Medicine

University of Basel and University Hospital Basel

Hebelstrasse 2

Basel, CH-4031

Switzerland

Phone: 41612655317

Email: gunther.meinlschmidt@unibas.ch

\section{Abstract}

Background: The gold standard management of aortic dissection, a life-threatening condition, includes multidisciplinary approaches. Although mental distress following aortic dissection is common, evidence-based psychosocial interventions for aortic dissection survivors are lacking.

Objective: The aim of this study is to identify the perceived psychosocial needs of aortic dissection survivors by surveying patients, their relatives, and health professionals to inform the development of such interventions.

Methods: This study used a cross-sectional survey and collected responses from 41 participants (27 patients with aortic dissection, 8 relatives of patients with aortic dissection, and 6 health professionals) on key topics, types of interventions, best timing, anticipated success, and the intended effects and side effects of psychosocial interventions after aortic dissection.

Results: The principal intervention topics were "changes in everyday life" (28/41, 68\%, 95\% CI 54.5\%-82.9\%), "anxiety" (25/41, 61\%, 95\% CI 46.2\%-76.2\%), “uncertainty" (24/41, 59\%, 95\% CI 42.9\%-73.2\%), “tension/distress" (24/41, 59\%, 95\% CI $43.9 \%-73.8 \%)$, and "trust in the body" (21/41, 51\%, 95\% CI 35.9\%-67.5\%). The most commonly indicated intervention types were "family/relative therapy" (21/41, 51\%, 95\% CI 35\%-65.9\%) and "anxiety treatment" (21/41, 51\%, 95\% CI 35\%-67.5\%). The most recommended intervention timing was "during inpatient rehabilitation" (26/41, 63\%, 95\% CI 47.6\%-77.5\%) followed by "shortly after inpatient rehabilitation" (20/41, 49\%, 95\% CI 32.4\%-65\%). More than 95\% (39/41) of respondents anticipated a benefit from psychosocial interventions following aortic dissection dissection, expecting a probable improvement in $68.6 \%$ (95\% CI 61.4\%-76.2\%) of aortic dissection survivors, a worse outcome for 5\% (95\% CI $2.9 \%-7.9 \%$ ), and that $6 \%$ (95\% CI $1.8 \%-10.4 \%$ ) would have negative side effects due to such interventions.

Conclusions: Our findings highlight a substantial need for psychosocial interventions in aortic dissection survivors and indicate that such interventions would be a success. They provide a basis for the development and evaluation of interventions as part of state-of-the-art aortic dissection management.

(J Participat Med 2020;12(3):e15447) doi: 10.2196/15447

\section{KEYWORDS}

aortic dissection; patient involvement; psychosocial support; psychosomatic; psychotherapy; treatment need 


\section{Introduction}

Aortic dissection is a rare but life-threatening condition. The annual incidence of the condition in older adults is up to 35 cases per 100,000 people, with a slight male preponderance [1-3]. This low incidence explains the delayed diagnosis; only $39 \%$ of patients are diagnosed within 24 hours after symptom onset [4]. Prognosis is grave, with a lethality rate of $1 \%$ to $2 \%$ per hour after onset of symptoms in untreated patients [5]. Preadmission mortality is $20 \%$ [6]. Operative 30-day mortality for ascending aortic dissection at experienced centers is still between $10 \%$ and $35 \%$ [4]. In a propensity-matched retrospective analysis, survival rates in patients with acute type A dissection were $91 \%$ after 30 days, $74 \%$ after 1 year, and $63 \%$ after 5 years [4]. Furthermore, 10-year survival rates of patients who are discharged from hospital range from $30 \%$ to $60 \%$ [6]. The underlying pathophysiology of aortic medial disease and defective wall structure confers an ongoing risk of further dissection, aneurysmal degeneration, and rupture. Therefore, consequent control of known risk factors is crucial. In addition to age and genetic disorders such as Marfan syndrome, risk factors include lifestyle factors such as long-term arterial hypertension, smoking, dyslipidemia, and cocaine, crack cocaine or amphetamine substance use [3]. All this can be highly traumatic and stressful for affected patients, their relatives, and health care professionals.

Contemporary management of aortic dissection should be multidisciplinary and include, among other things, serial noninvasive imaging, biomarker testing, genetic risk profiling for aortopathy, blood pressure and heart rate control, lipid-lowering therapies, and repairing or replacing the damaged region of the aorta $[2,3,7]$, with evidence that successful surgical intervention substantially improves the quality of life of aortic dissection survivors [8-10].

With regard to psychosocial factors, previous recommendations focus on patient education and the achievement of lifestyle goals. They include ensuring adherence to medical treatment, genetic counselling, smoking cessation, and other risk factor modification for atherosclerotic disease, as well as avoidance of cocaine or other stimulating drugs [2]. Furthermore, counselling aortic dissection survivors on exercise and physical activity has been described as important yet challenging, given the need to ensure avoidance of potentially damaging strenuous physical activities and contact sports, while fostering moderate intensity cardiovascular activity that may be cardioprotective in this patient cohort [11].

Initial evidence showed changes in lifestyle and emotional state following aortic dissection, with physical and sexual activity decreasing slightly, the latter mostly in relation to fear, while approximately one-third of aortic dissection survivors reported new subjective feelings of depression and anxiety [12]. However, anecdotal reports suggest that regular provision of psychosocial support to aortic dissection survivors, including psychotherapy and other interventions for psychosocial distress or mental disorders, is scarce.

Despite common clinical observations of psychosocial distress related to aortic dissection, to the best of our knowledge, there is no evidence-based tailored psychosocial (ie, psychosomatic or psychotherapeutic) intervention for aortic dissection survivors, or even systematic information regarding the need for psychosocial interventions following aortic dissection. Therefore, as a first step toward the development of a tailored psychosocial support intervention for aortic dissection survivors, we conducted a survey, addressing aortic dissection survivors, relatives of aortic dissection survivors, and professionals working with patients with aortic dissection.

The main aims of this survey were to systematically identify (1) the key topics that need psychosocial attention for aortic dissection survivors, (2) the main types of desired psychosocial interventions, (3) the expected success and both the intended and unintended effects of such interventions, and (4) the preferred timing of such interventions.

Our study is in line with recent efforts to involve patients early in the development of new interventions, which has become a key issue in biomedical research (eg, see the British Medical Journal's Partnering with Patients initiative ("nothing about us without us") [13]. According to this movement, partnering with patients, their families, support communities, and the public is an ethical imperative, which is essential to improving the quality, safety, value, and sustainability of health care systems.

\section{Methods}

\section{Study Setting and Design}

We present the results from a cross-sectional survey administered during an aortic dissection information event (Aortic Dissection Awareness Day 2017) to aortic dissection survivors and their families and relatives, as well as health professionals dealing with this condition at the University Hospital Basel.

Ethical clearance for this study was acquired from the Ethikkommission Nordwest- und Zentralschweiz (EKNZ) in Basel, Switzerland (EKNZ BASEC Req-2017-00916). Each participant provided consent that his/her responses could be used for analyses that would be reported in scientific publications.

We describe the results of our survey based on the Guidance for Reporting Involvement of Patients and the Public (GRIPP) 2 , the first international guidance for reporting of patient and public involvement in health and social care research [14]. The GRIPP2 short form checklist short form accompanying this article is provided as Multimedia Appendix 1.

\section{Study Instrument}

The questionnaire we used was a self-developed instrument compiled by an interdisciplinary team. The contents of the questionnaire, including the response categories, were compiled over the course of several meetings on the basis of pertinent publications $[12,15]$ and information obtained during clinical encounters with patients with aortic dissection. We added open response options to ensure that respondents could provide replies beyond the preselected categories. Draft versions of the questionnaire were circulated and, based on written feedback and exchanges during another meeting, the instrument was 
modified until consensus was reached. This resulting questionnaire covers respondents' sociodemographic information, topics that may require psychosocial attention for aortic dissection survivors and their relatives, types of psychosocial interventions preferred, the expected intended and unintended effects and anticipated success of such interventions, and the preferred timing of such interventions. Furthermore, we asked the respondents to indicate the percentage of aortic dissection survivors they knew that had received psychosocial support or interventions, and to specify the support or interventions. Finally, we left space for additional comments.

Answer formats were predominantly prespecified response categories that allowed for additional open responses. Other questions used a 7-point Likert-scale ("strongly disagree" to "strongly agree"), or asked for frequencies expressed as percentages.

A professional translator ensured equivalence of the French and German versions of the questionnaire. An English translation of the questionnaire is provided as Multimedia Appendix 2. The German and French versions are available from the authors on request.

\section{Recruitment of Respondents}

During an aortic dissection information event, Aortic Dissection Awareness Day 2017, we administered a paper-pencil version of our questionnaire in German and French, enabling anonymous responses. The event was open to the public and participants included aortic dissection survivors and their families and relatives, as well as health professionals dealing with this condition. All attendees were invited to participate in the survey, without any predetermined number of participants being asked to complete the survey. We included responses from aortic dissection survivors, their families and relatives, and health professionals.

\section{Analyses and Statistics}

We analyzed the responses by using descriptive statistics, calculating means and frequencies, and estimating 95\% confidence intervals (95\% CIs), based on bootstrapping procedures (1000 repetitions), to provide a measure of accuracy to our findings in terms of estimates. We did not apply the bootstrapping procedure in cases where the subgroup sample size was insufficient to calculate meaningful CIs (in these cases, no $95 \%$ CIs are provided). We provide analyses for the total sample and stratified analyses according to (1) aortic dissection survivors, (2) relatives of aortic dissection survivors, and (3) health professionals concerned with patients with aortic dissection. Open answers and comments were evaluated according to the principles of Qualitative Content Analysis [16]. Statistical analyses were performed using IBM SPSS Statistics for Macintosh (Version 21.0, IBM Corp).

\section{Results}

\section{Study Sample Characteristics}

A total of 41 aortic dissection survivors, their families and relatives, and health professionals participated in the study and consented to the use of their information for research purposes. In addition, 3 participants ( 2 partially, 1 fully) completed the questionnaire without consenting to the use of their information for research purposes. Data from these 3 subjects ( $7 \%$ of eligible respondents) and data from 3 noneligible respondents (who did not fall under one of the 3 subgroups surveyed in this study; $6 \%$ of all respondents) were excluded from analyses. The majority of the 41 subjects included in the study were patients with aortic dissection $(n=27)$, followed by relatives of patients with aortic dissection $(n=8)$, and health professionals $(n=6)$. The characteristics of the study sample are presented in the table below (Table 1). 
Table 1. Characteristics of the study sample.

\begin{tabular}{|c|c|c|c|c|}
\hline Characteristics & $\begin{array}{l}\text { Patients with aortic dissection } \\
(\mathrm{n}=27), \mathrm{n}(\%)\end{array}$ & $\begin{array}{l}\text { Relatives of patients with aortic } \\
\text { dissection }(\mathrm{n}=8), \mathrm{n}(\%)\end{array}$ & Health professionals $(\mathrm{n}=6), \mathrm{n}(\%)$ & All subjects $(\mathrm{n}=41), \mathrm{n}(\%)$ \\
\hline \multicolumn{5}{|l|}{ Gender } \\
\hline Male & $21(84)$ & $0(0)$ & $4(67)$ & $25(69)$ \\
\hline Female & $4(16)$ & $5(100)$ & $2(33)$ & $11(31)$ \\
\hline No response ${ }^{\mathrm{a}}$ & 2 & 3 & $\mathrm{~N} / \mathrm{A}^{\mathrm{b}}$ & 5 \\
\hline \multicolumn{5}{|l|}{ Age (years) } \\
\hline$<30$ & $1(4)$ & $0(0)$ & $2(33)$ & $3(7)$ \\
\hline $30-39$ & $0(0)$ & $1(13)$ & $0(0)$ & $1(2)$ \\
\hline $40-49$ & $3(11)$ & $0(0)$ & $3(50)$ & $6(15)$ \\
\hline $50-59$ & $7(26)$ & $2(25)$ & $1(17)$ & $10(24)$ \\
\hline $60-69$ & $10(37)$ & $4(50)$ & $0(0)$ & $14(34)$ \\
\hline$>69$ & $6(22)$ & $1(13)$ & $0(0)$ & $7(17)$ \\
\hline \multicolumn{5}{|l|}{ Language } \\
\hline German & $26(96)$ & $8(100)$ & $6(100)$ & $40(98)$ \\
\hline French & $1(4)$ & $0(0)$ & $0(0)$ & $1(2)$ \\
\hline \multicolumn{5}{|c|}{ Number of other patients with aortic dissection in contact with in a year } \\
\hline None & $17(68)$ & $2(25)$ & $1(17)$ & $20(51)$ \\
\hline $1-3$ patients & $8(32)$ & $6(75)$ & $2(33)$ & $16(41)$ \\
\hline 4-8 patients & $0(0)$ & $0(0)$ & $0(0)$ & $0(0)$ \\
\hline 9-19 patients & $0(0)$ & $0(0)$ & $0(0)$ & $0(0)$ \\
\hline 20-40 patients & $0(0)$ & $0(0)$ & $1(17)$ & $1(3)$ \\
\hline$\geq 40$ patients & $0(0)$ & $0(0)$ & $2(33)$ & $2(5)$ \\
\hline No response ${ }^{\mathrm{a}}$ & 2 & N/A & N/A & 2 \\
\hline
\end{tabular}

${ }^{\mathrm{a}}$ Where participants did not respond to a question, they were not counted in the percentage calculations.

${ }^{b}$ N/A: not applicable.

\section{Key Topics}

On average, 6 topics (95\% CI 5.2-6.9; Table 2) that need psychosocial attention after aortic dissection were indicated per respondent. The most common topics (Figure 1), all chosen by more than half of the respondents, were "changes in everyday life" (28/41, 68\%, 95\% CI 54.5\%-82.9\%), "anxiety" (25/41, $61 \%, 95 \%$ CI $46.2 \%-76.2 \%)$, "uncertainty" (24/41, 59\%, $95 \%$ CI 42.9\%-73.2\%), "tension/stress" (24/41, 59\%, 95\% CI $43.9 \%-73.8 \%)$, and "trust in the body" $(21 / 41,51 \%, 95 \% \mathrm{CI}$ $35.9 \%-67.5 \%$ ). The only additional topics in the free response category were "insurance issues" and "pension issues" mentioned by 1 aortic dissection survivor.

Compared to aortic dissection survivors, relatives of patients with aortic dissection indicated "anxiety," "sexuality," and "sleep" more often and "open medical questions" and "exercise/sport" less often (none indicated "open medical questions"). Health care professionals indicated "exercise/sport," "return to former (professional) life," and "open medical questions" less often than aortic dissection survivors (none indicated "open medical questions"). 
Figure 1. Frequency of subjects mentioning a certain concern or topic of interest to aortic dissection survivors to be addressed by psychosocial-psychotherapeutic interventions (mean and 95\% CI). AOD: aortic dissection.

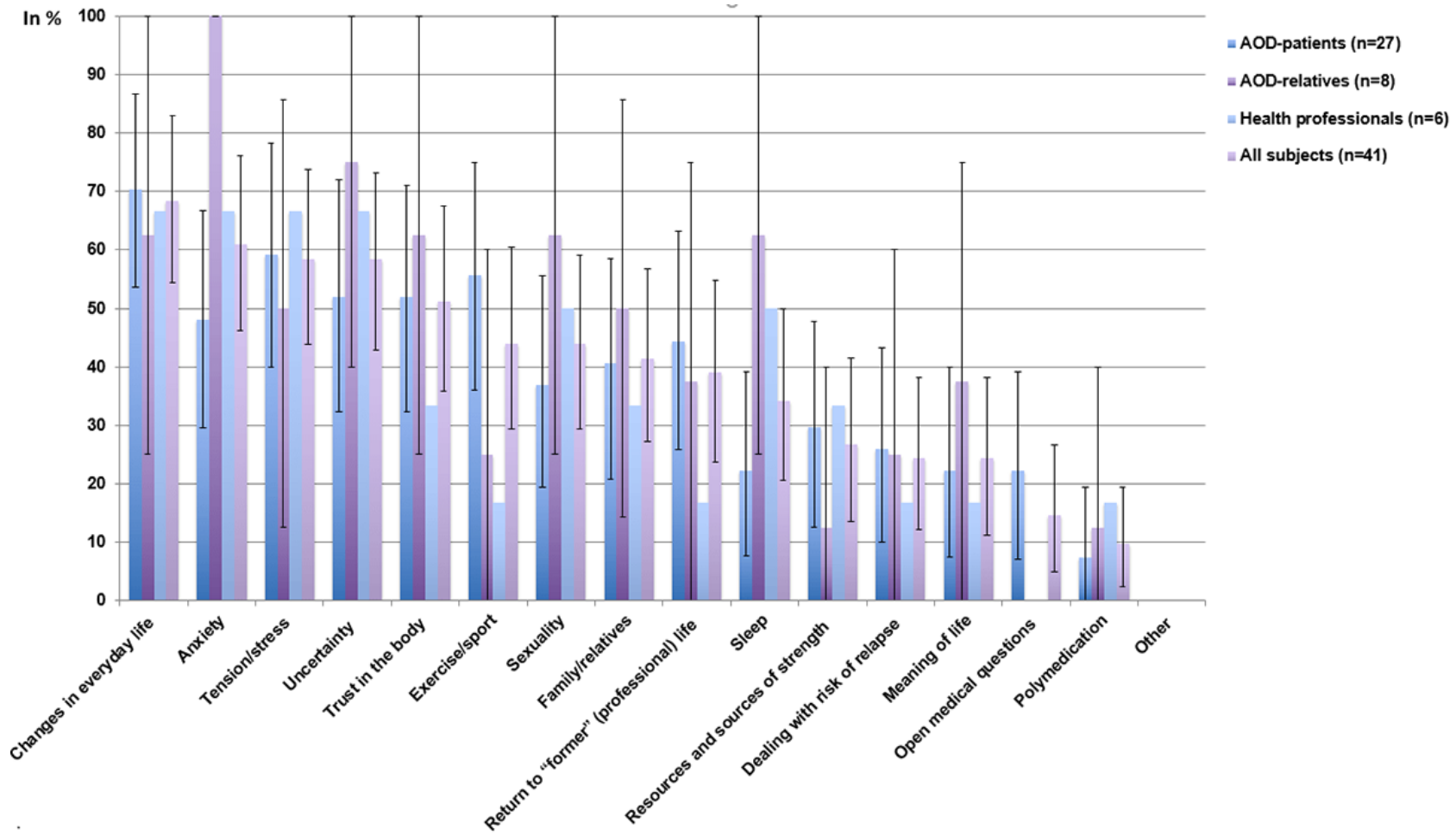

\section{Types of Psychosocial Interventions Preferred}

On average, each respondent indicated 4 different types (95\% CI 3.3-4.7) of desired psychosocial interventions for aortic dissection survivors. The most common types (Figure 2), indicated by more than half of the respondents, were "family/relative therapy" $(21 / 41,51 \%, 95 \%$ CI 35\%-65.9\%) and "anxiety treatment" (21/41, 51\%, 95\% CI 35\%-67.5\%). In addition, 2 aortic dissection survivors used the free response option to add "help with clarifications regarding insurance and pension issues" and "obtaining a better understanding of what residual impairment is "normal' after aortic dissection."

Figure 2. Frequency of subjects mentioning a certain type of psychosocial-psychotherapeutic intervention being of relevance to aortic dissection survivors (mean and 95\% CI). AOD: aortic dissection.

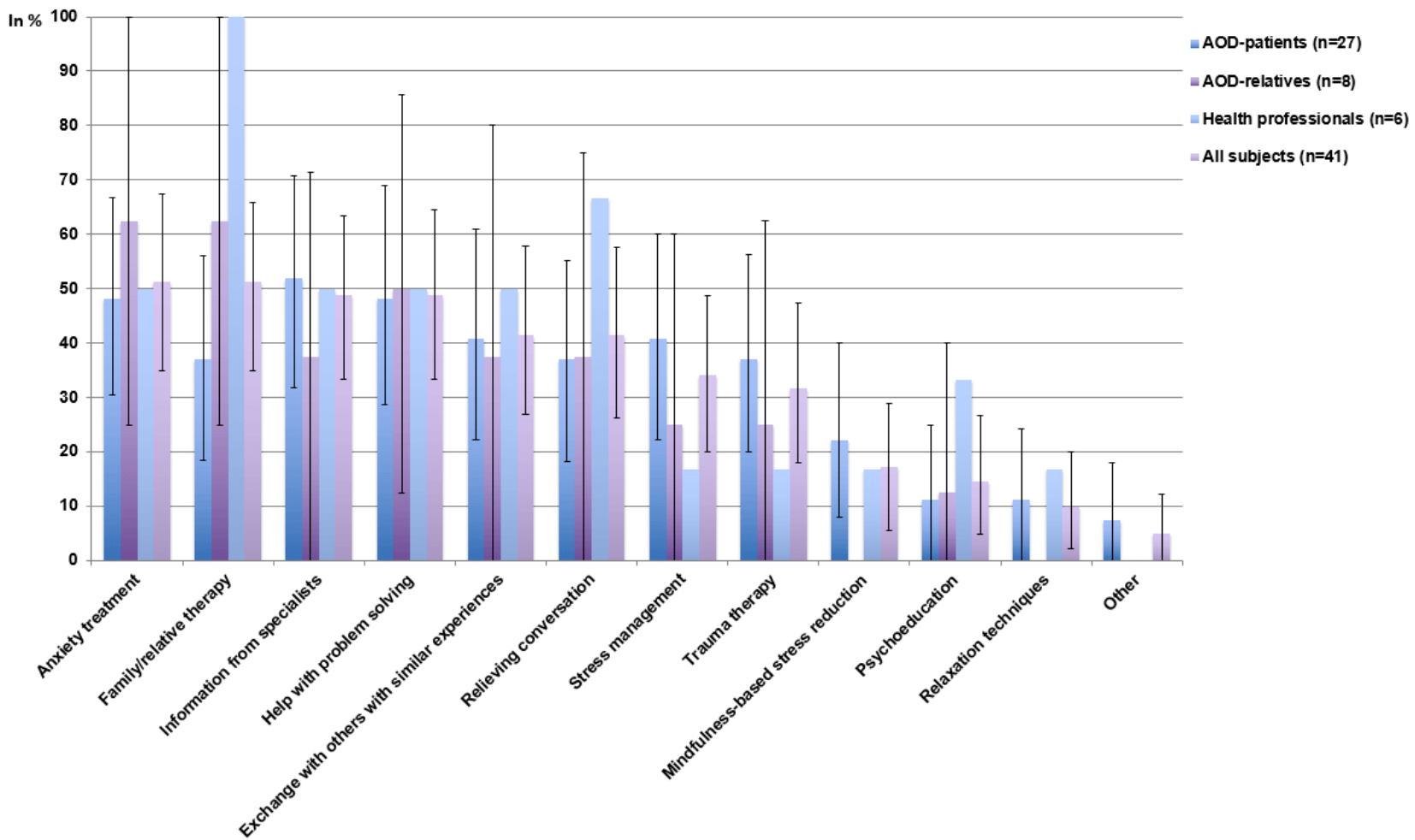


Compared to aortic dissection survivors, relatives indicated "family/relative therapy" more often and "mindfulness-based stress reduction" (MBSR) and "relaxation techniques" less often (not at all). Compared to aortic dissection survivors, health care professionals chose "family/relative therapy," "relieving conversation," and "psychoeducation" more often, and "stress-management" and "trauma therapy" less often.

\section{Best Timing of Intervention}

The most commonly chosen appropriate time to propose psychosocial support after aortic dissection was "during inpatient rehabilitation" (26/41, 63\%, 95\% CI 47.6\%-77.5\%) followed by "shortly after inpatient rehabilitation" $(20 / 41,49 \%, 95 \%$ CI $32.4 \%-65 \%)$, "at outpatient follow-up" (16/41, 39\%, $95 \%$ CI $24.4 \%-54.7 \%)$, and "within two weeks after acute treatment" $(11 / 41,27 \%, 95 \%$ CI 14\%-41.9\%; Figure 3).

Figure 3. Frequency of subjects proposing a certain time as appropriate for psychosomatic or psychotherapeutic support after aortic dissection (mean and $95 \% \mathrm{CI}$ ). AOD: aortic dissection.

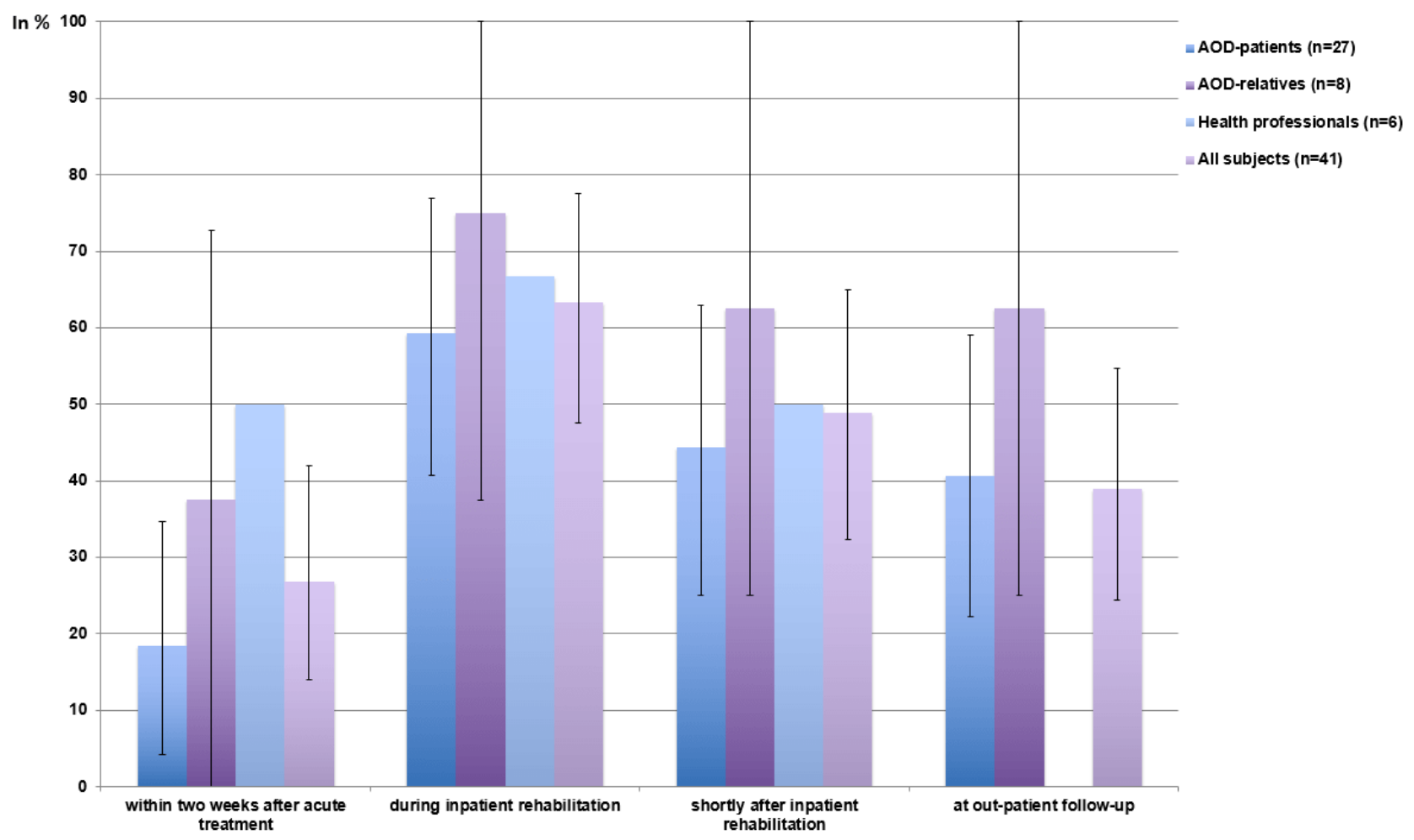

\section{Anticipated Success}

More than 95\% (39/41) of respondents "strongly agreed" (20/41, 49\%, 95\% CI 33.3-64.3), "agreed” (12/41, 29\%, 95\% CI 15.9-44.5), or "somewhat agreed" (7/41, 17\%, 95\% CI 5.4-28.9) that patients would benefit from psychosocial support after aortic dissection, with relatives and health care professionals being slightly more optimistic than aortic dissection survivors (Figure 4; mean scores provided in Table 2).

\section{Intended Effects and Side Effects}

In total, a mean of $68.6 \%$ of respondents expected that aortic dissection survivors (95\% CI 61.4-76.2) would improve due to psychosocial support, while a mean of 5.2\% (95\% CI 2.9-7.9) expected they would be worse off. Furthermore, a mean of $5.7 \%$ of aortic dissection survivors (95\% CI 1.8-10.4) expected to experience negative side effects from psychosocial support (Table 2).

Types of expected side effects were only indicated by aortic dissection survivors and included the following: "other problems predominately," "depression," "stress," "the fears are greater than the support suggests," "egocentric manifestations," "fear of relapse," and "to focus too much on the disease when the ability to work is restored."

\section{Qualitative Findings}

Answers to the open question "What else would you consider important to improve psychosomatic or post-aortic dissection psychotherapeutic support?" were sorted according to the categories identified and are provided in Table 3 . The majority of responses can be subsumed under the categories "emotional support and encouragement" and "information, counsel, and assistance." 
Figure 4. Frequency of subjects agreeing that patients would benefit from psychotherapeutic support after aortic dissection (mean and 95\% CI). AOD: aortic dissection.

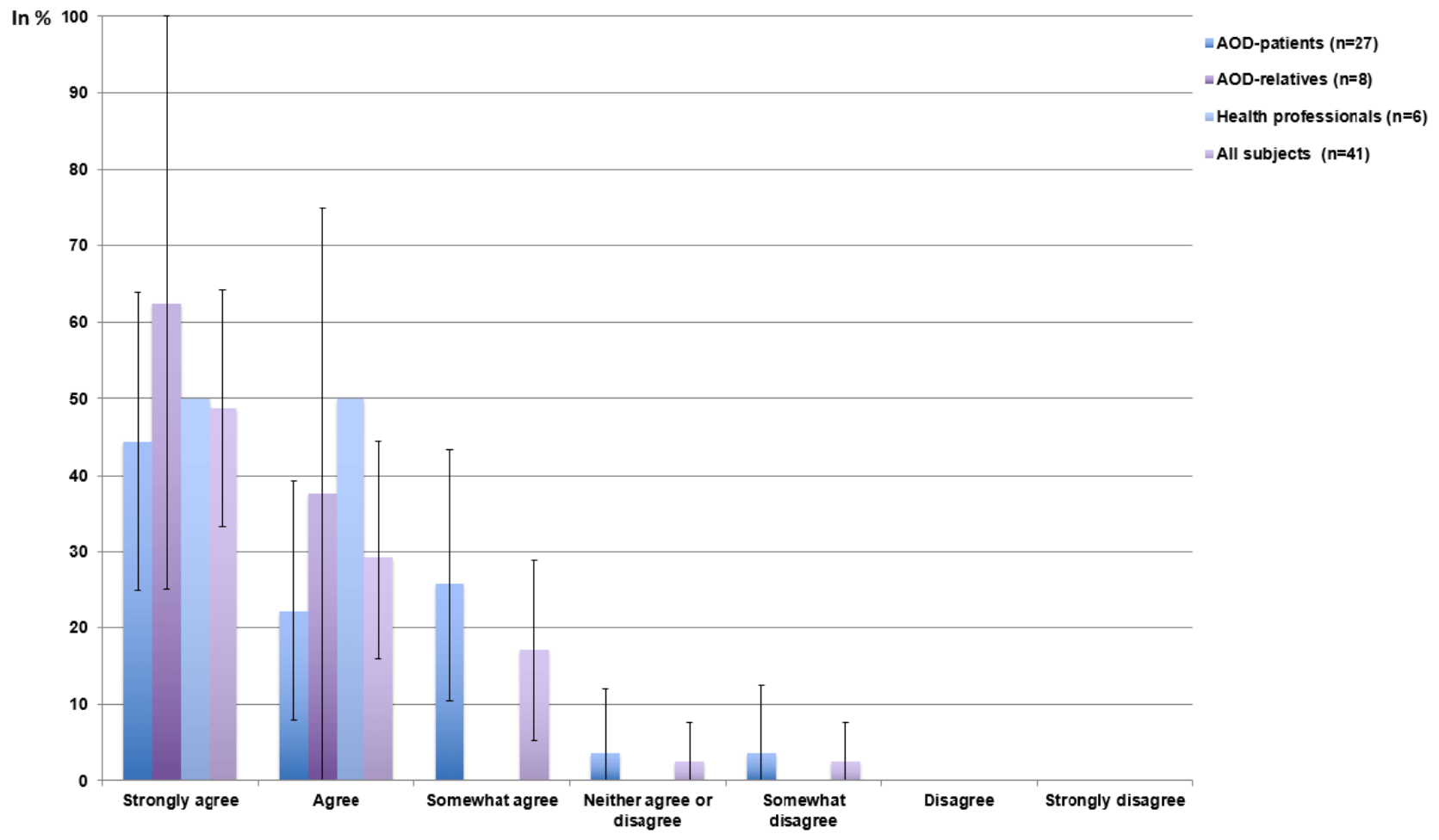

Table 2. Survey results and continuous variables.

\begin{tabular}{|c|c|c|c|c|c|}
\hline Variable & Scale & $\begin{array}{l}\text { Patients with aortic } \\
\text { dissection }(\mathrm{n}=27) \text {, } \\
\text { mean }(95 \% \mathrm{CI})\end{array}$ & $\begin{array}{l}\text { Relatives of patients } \\
\text { with aortic dissection } \\
(\mathrm{n}=8) \text {, mean }(95 \% \mathrm{CI})^{\mathrm{a}}\end{array}$ & $\begin{array}{l}\text { Health professionals } \\
(\mathrm{n}=6) \text {, mean }(95 \% \mathrm{CI})^{\mathrm{a}}\end{array}$ & $\begin{array}{l}\text { All subjects }(\mathrm{n}=41) \text {, } \\
\text { mean }(95 \% \mathrm{CI})\end{array}$ \\
\hline $\begin{array}{l}\text { Extent of agreement with } \\
\text { "Patient would benefit } \\
\text { from interventions" }\end{array}$ & $\begin{array}{l}1 \text { (strongly disagree) } \\
\text { to } 7 \text { (strongly agree) }\end{array}$ & $6(5.57-6.4)$ & $6.63(6.25-7)$ & $6.5(6-7)$ & $6.2(5.9-6.5)$ \\
\hline $\begin{array}{l}\text { Expected frequency of } \\
\text { aortic dissection sur- } \\
\text { vivors that improve }\end{array}$ & Percentages & $66.7(56.9-76.4)$ & $70(53.8-85.5)$ & 75 & $68.6(61.4-76.2)$ \\
\hline $\begin{array}{l}\text { Expected frequency of } \\
\text { aortic dissection sur- } \\
\text { vivors that decline }\end{array}$ & Percentages & $5.5(2.9-8.2)$ & $5(5-5)$ & 4.2 & $5.2(2.9-7.9)$ \\
\hline $\begin{array}{l}\text { Expected frequency of } \\
\text { aortic dissection sur- } \\
\text { vivors with negative side } \\
\text { effects }\end{array}$ & Percentages & $9.1(3.4-16.4)$ & 0 & 0.8 & $5.7(1.9-10.4)$ \\
\hline $\begin{array}{l}\text { Frequency of acquain- } \\
\text { tances receiving psy- } \\
\text { chosocial treatment }\end{array}$ & Percentages & $2.2(0-6.7)$ & $16.7(0-50)$ & 35 & $12.5(0.8-28.9)$ \\
\hline $\begin{array}{l}\text { Number of mentioned } \\
\text { topics of aortic dissection } \\
\text { survivors that need psy- } \\
\text { chosocial attention per } \\
\text { respondent }\end{array}$ & Absolute frequency & $5.9(4.7-7.1)$ & $6.8(5.6-8)$ & 5.5 & $6(5.2-6.9)$ \\
\hline $\begin{array}{l}\text { Number of mentioned } \\
\text { types of desired psychoso- } \\
\text { cial interventions per re- } \\
\text { spondent }\end{array}$ & Absolute frequency & $3.9(3.1-4.8)$ & $3.5(2.5-4.5)$ & 4.7 & $4(3.3-4.7)$ \\
\hline
\end{tabular}

${ }^{\mathrm{a}} 95 \%$ CI was calculated given sufficient sample size and distribution of values. 
Table 3. Open answers to the question "What else would you consider important to improve psychosomatic or post-aortic dissection psychotherapeutic support?"

\begin{tabular}{ll}
\hline Type of respondent and response & Category
\end{tabular}

Patients with aortic dissection

Encouraging conversation

Emotional support, encouragement

Being accompanied

Emotional support, encouragement

That one deals with the patient intensively and really does not give up

Emotional support, encouragement

I was supported by [name of physician]. That carried me through the operation and recov- Emotional support, encouragement ery

To help people who need invalidity insurance after aortic dissection, in the fight with the Information, counsel, assistance insurance company and the pension fund

Support with invalidity insurance

Emotional support, encouragement

Family support

Family

Inclusion of relatives and starting during rehabilitation

Family

That the option is offered and that relatives can access help both now and later

Family

With mechanical heart valve (how to deal with the sound)

Information, counsel, assistance

That a consultation is offered as early as possible. Similar to care teams after suicide or comparable events. I had to fight to receive a psychological conversation during rehabilitation. Thereafter, psychotherapy.

Assistance in dealing with AHV/IV (pension insurance invalidity insurance)/pension fund, etc. Clarification of financial situation.

Workplace: What work can I still do?

Information, counsel, assistance

To provide necessary information (addresses) of contacts after leaving the hospital (eg, cardiologist, psychologist, etc)

To inform patients and their relatives early regarding opportunities for support

You should go back to "everyday life" but still take care

Information, counsel, assistance

Not getting good sleep

Reintegration into the work process is a challenge for indefinable reasons (difficult-toexplain symptoms)

Information, counsel, assistance

Information, counsel, assistance

Information, counsel, assistance

Topics

Topics

Topics

Emotional support, encouragement

Family

Family

Emotional support, encouragement Information, counsel, assistance

Information, counsel, assistance insurance

To reduce fear by education

\section{Health professionals}

To reduce fear through better information

Information, counsel, assistance

\section{Already Received Psychosocial Support}

The average percentage of aortic dissection survivors that have received psychosocial support or treatment known to the respondents was $12.5 \%$ (95\% CI 0.8\%-28.9\%; Table 2).

The type of support received included "relaxation exercises," "exercise/sport," "nutrition," "support from psychologist already received because of severe arthritis and claustrophobia," "self-organized after rehabilitation," "the family doctor provided a lot of support with conversation, etc," and "my partner was looking for support himself."

\section{Discussion}

In line with current patient involvement standards and to inform the development of psychosocial interventions, this study aimed to identify the needs of aortic dissection survivors, as indicated by aortic dissection survivors, their relatives, and health care professionals.

The most common topics to be addressed with such interventions included "disturbances in everyday life," "anxiety," "uncertainty," "tension/stress," and "trust in the body." The preferred types of interventions included "family/relative 
therapy" and "anxiety treatment." The top recommended intervention timing was "during inpatient rehabilitation" followed by "shortly after inpatient rehabilitation." Respondents anticipated that aortic dissection survivors would largely benefit from psychosocial interventions, on average expecting that approximately two-thirds would improve while only few would worsen or experience negative side effects.

Our study confirms the clinical impression that as current practice, only a minority of aortic dissection survivors receive psychosocial support, and if they do, it is limited to very few topics, such as exercise, sports, or anxiety.

Our findings are in line with and extend previous evidence on aortic dissection survivors, underlining the relevance of anxiety and uncertainty, topics related to activity, sports, and exercise, as well as sexuality after aortic dissection [12]. However, our findings also highlight hitherto unidentified topics, such as "trust in the body," "tension or stress," "everyday and professional life," as well as "family and relatives." Furthermore, the topics identified here are compatible with and expand reports on patients with unspecified life-threatening diseases in the context of intensive care units, with previous reports highlighting anxiety, uncertainty, and stress [17].

As the study comprised far fewer relatives and health professionals than aortic dissection survivors, conclusions based on comparisons between these groups' responses need to be drawn with caution. Nevertheless, our findings suggest that while there appeared to be a large overlap of views across these groups, there were also relevant differences (eg, compared to aortic dissection survivors, relatives mentioned anxiety and uncertainty more often as topics to address, and family/relative therapy as a desired intervention).

\section{Strengths and Limitations}

Our study has several strengths. We not only approached aortic dissection survivors and professionals, but also relatives of aortic dissection survivors, adding a perspective relevant to aortic dissection survivors' needs and expectations regarding psychosocial interventions. Furthermore, we assessed a broad spectrum of potential intervention topics and types, complemented by open questions, thereby embracing a broad range of needs regarding psychosocial interventions after aortic dissection. Our study also has several limitations: (1) By recruiting subjects as a convenience sample on an aortic dissection information day, we cannot exclude selection bias, potentially limiting the generalizability of our findings. However, the age and gender ratio of aortic dissection survivors participating in the survey was largely comparable to previous reports [18]. (2) The sample consisted primarily of aortic dissection survivors, and included a rather small number of relatives and health care professionals. All relatives that participated in the survey and provided gender information were female, highlighting the need to approach male relatives of aortic dissection survivors in future studies. (3) Given the moderate sample size, we did not stratify analyses with regard to age group, gender, or subtypes of aortic dissection. However, there is no clear rationale as to why a certain subtype of aortic dissection should have a risk profile different than that of other subtypes.

\section{Implications for Research and Clinical Practice}

Future studies should increase the number of respondents, including relatives of patients with aortic dissection as well as health professionals with different specializations (cardiologists, psychiatrists, etc); address additional questions, such as the preferred setting of psychosocial interventions (individual face-to-face versus group face-to-face versus online interventions); and expand the response categories to include additional topics, such as substance use.

The results of our study have important clinical implications. They guide the development of psychosocial interventions for aortic dissection survivors and their relatives in several ways: (1) the results highlighted the large number and substantial variety of issues that should be targeted, suggesting that a modular approach that allows a tailored and personalized compilation of intervention modules and techniques may be required to appropriately address diverse and complex individual needs; (2) they underscored the importance of potentially involving family and relatives and addressing related topics; (3) the results indicated potential undesired effects, such as iatrogenic fixation onto fears and the disease, hindering the focus necessary for restoration of participation in daily life and working ability; and (4) they suggested that interventions should be available along the whole disease period, from acute treatment directly after aortic dissection, to inpatient rehabilitation and the time thereafter, including outpatient follow-up.

We are currently establishing consultation-liaison psychosomatic support for patients with aortic dissection, informed by the findings reported here. To this end, we consider the individual needs of each patient and her or his family to develop interventions that fit each support-seeker best.

\section{Conclusions}

In this study, we described the results from a survey answered by aortic dissection survivors, their relatives, and health care professionals. These results provide a basis to inform the development of tailored psychosocial interventions. Overall, patient involvement was very well perceived and feasible, suggesting that it should become common practice when developing new psychosocial interventions in cardiology and beyond. Our findings highlight a substantial need and the anticipated success of psychosocial interventions for aortic dissection survivors and their relatives, and provide the basis for the development and evaluation of therapies that could become part of state-of-the-art aortic dissection management.

\section{Acknowledgments}

The authors thank Claudia Steiner for correcting the English version of the questionnaire. We are grateful to Iris Feigenwinter for supporting the preparation of the manuscript. 
GM, SH, and RS received funding from the Stanley Thomas Johnson Stiftung, Gottfried und Julia Bangerter-Rhyner-Stiftung, and the Swiss Cancer League (Krebsliga Schweiz) under project numbers PC_28/17, PC_05/18, and KLS-4304-08-2017, respectively. GM and RS received funding from Gesundheitsförderung Schweiz under project number 18.191. GM received funding from the National Research Foundation of Korea within the Global Research Network Program under project number 2013S1A2A2035364, from the Research Foundation of the International Psychoanalytic University (IPU) Berlin, and from the Swiss National Science Foundation (SNSF) under project number 100014_135328. RS received funding from the Köhler Foundation under project number SO112/10209/16. The funding sources had no involvement in study design; the collection, analysis, and interpretation of the data; the writing of the report; and the decision to submit the article for publication.

\section{Authors' Contributions}

GM, RM, AF, SH, and RS conceptualized and designed the survey. GM and SG conducted statistical analyses. GM, RM, AF, $\mathrm{SH}$, and RS interpreted data. GM wrote the initial manuscript. DB, RM, AF, SG, US, FSE, SH, and RS critically reviewed the manuscript. GM, DB, RM, AF, SG, US, FSE, SH, and RS approved the final version of the manuscript.

\section{Conflicts of Interest}

None declared.

\section{Multimedia Appendix 1}

GRIPP2 checklist.

[DOCX File, 16 KB-Multimedia Appendix 1]

\section{Multimedia Appendix 2}

Questionnaire.

[DOCX File, 642 KB-Multimedia Appendix 2]

\section{References}

1. Howard DPJ, Banerjee A, Fairhead JF, Perkins J, Silver LE, Rothwell PM, Oxford Vascular Study. Population-based study of incidence and outcome of acute aortic dissection and premorbid risk factor control: 10-year results from the Oxford Vascular Study. Circulation 2013 May 21;127(20):2031-2037 [FREE Full text] [doi:

10.1161/CIRCULATIONAHA.112.000483] [Medline: 23599348]

2. Bossone E, LaBounty TM, Eagle KA. Acute aortic syndromes: diagnosis and management, an update. Eur Heart J 2018 Mar 01;39(9):739-749d. [doi: 10.1093/eurheartj/ehx319] [Medline: 29106452]

3. Nienaber CA, Clough RE, Sakalihasan N, Suzuki T, Gibbs R, Mussa F, et al. Aortic dissection. Nat Rev Dis Primers 2016 Dec 25;2:16071. [doi: 10.1038/nrdp.2016.71] [Medline: 27560366]

4. Nienaber CA, Clough RE. Management of acute aortic dissection. Lancet 2015 Feb 28;385(9970):800-811. [doi: 10.1016/S0140-6736(14)61005-9] [Medline: 25662791]

5. Gawinecka J, Schönrath F, von Eckardstein A. Acute aortic dissection: pathogenesis, risk factors and diagnosis. Swiss Med Wkly 2017;147:w14489 [FREE Full text] [doi: 10.4414/smw.2017.14489] [Medline: 28871571]

6. Thrumurthy SG, Karthikesalingam A, Patterson BO, Holt PJE, Thompson MM. The diagnosis and management of aortic dissection. BMJ 2011 Jan 11;344:d8290. [doi: 10.1136/bmj.d8290] [Medline: 22236596]

7. Nienaber CA, Divchev D, Palisch H, Clough RE, Richartz B. Early and late management of type B aortic dissection. Heart 2014 Oct;100(19):1491-1497. [doi: 10.1136/heartjnl-2013-305133] [Medline: 25092877]

8. Lohse F, Lang N, Schiller W, Roell W, Dewald O, Preusse C, et al. Quality of life after replacement of the ascending aorta in patients with true aneurysms. Tex Heart Inst J 2009;36(2):104-110 [FREE Full text] [Medline: 19436802]

9. Kobuch R, Schelker E, Schmid C, Hirt S, Amann M, Diez C. Quality of life following surgery of ascending aorta and aortic arch with selective antegrade cerebral perfusion. Thorac Cardiovasc Surg 2012 Dec;60(8):496-500. [doi:

10.1055/s-0031-1299583] [Medline: 22399311]

10. Immer FF, Lippeck C, Barmettler H, Berdat PA, Eckstein FS, Kipfer B, et al. Improvement of quality of life after surgery on the thoracic aorta: effect of antegrade cerebral perfusion and short duration of deep hypothermic circulatory arrest. Circulation 2004 Sep 14;110(11 Suppl 1):II250-II255. [doi: 10.1161/01.CIR.0000138387.61103.a0] [Medline: 15364871]

11. Chaddha A, Eagle KA, Braverman AC, Kline-Rogers E, Hirsch AT, Brook R, et al. Exercise and Physical Activity for the Post-Aortic Dissection Patient: The Clinician's Conundrum. Clin Cardiol 2015 Nov;38(11):647-651 [FREE Full text] [doi: 10.1002/clc.22481] [Medline: 26769698]

12. Chaddha A, Kline-Rogers E, Braverman AC, Erickson SR, Jackson EA, Franklin BA, et al. Survivors of Aortic Dissection: Activity, Mental Health, and Sexual Function. Clin Cardiol 2015 Nov;38(11):652-659 [FREE Full text] [doi: 10.1002/clc.22418] [Medline: 26769699] 
13. Chu LF, Utengen A, Kadry B, Kucharski SE, Campos H, Crockett J, et al. Nothing about us without us-patient partnership in medical conferences. BMJ 2016 Sep 14;354:i3883 [FREE Full text] [doi: 10.1136/bmj.i3883] [Medline: 27628427]

14. Staniszewska S, Brett J, Simera I, Seers K, Mockford C, Goodlad S, et al. GRIPP2 reporting checklists: tools to improve reporting of patient and public involvement in research. BMJ 2017 Aug 02;358:j3453 [FREE Full text] [doi: 10.1136/bmj.j3453] [Medline: 28768629]

15. Velvin G, Bathen T, Rand-Hendriksen S, Geirdal AO. Satisfaction with life in adults with Marfan syndrome (MFS): associations with health-related consequences of MFS, pain, fatigue, and demographic factors. Qual Life Res 2016 Jul;25(7):1779-1790. [doi: 10.1007/s11136-015-1214-1] [Medline: 26727916]

16. Mayring P. Social Science Open Access Repository. 2014. Qualitative content analysis: Theoretical foundation, basic procedures and software solution URL: http://www.ssoar.info/ssoar/handle/document/39517 [accessed 2015-12-17] [WebCite Cache ID 6dqxR8a4Z]

17. Abrahamian H, Lebherz-Eichinger D. The role of psychosomatic medicine in intensive care units. Wien Med Wochenschr 2018 Mar;168(3-4):67-75. [doi: 10.1007/s10354-017-0575-1] [Medline: 28616666]

18. Isselbacher EM, Bonaca MP, Di Eusanio M, Froehlich J, Bassone E, Sechtem U, et al. Recurrent Aortic Dissection. Circulation 2016 Oct 04;134(14):1013-1024. [doi: 10.1161/circulationaha.115.019359] [Medline: 27587434]

\title{
Abbreviations \\ EKNZ: Ethikkommission Nordwest- und Zentralschweiz \\ GRIPP: Guidance for Reporting Involvement of Patients and the Public \\ IPU: International Psychoanalytic University \\ SNSF: Swiss National Science Foundation
}

\author{
Edited by S Woods, A Powell; submitted 15.07.19; peer-reviewed by J Schultz, N Beckwith, T Ungar; comments to author 03.09.19; \\ revised version received 20.01.20; accepted 28.02.20; published 06.07.20 \\ Please cite as: \\ Meinlschmidt G, Berdajs D, Moser-Starck R, Frick A, Gross S, Schurr U, Eckstein FS, Hunziker S, Schaefert R \\ Perceived Need for Psychosocial Support After Aortic Dissection: Cross-Sectional Survey \\ J Participat Med 2020;12(3): 15447 \\ URL: https://jopm.jmir.org/2020/3/e 15447 \\ doi: $10.2196 / 15447$ \\ PMID:
}

CGunther Meinlschmidt, Denis Berdajs, Roger Moser-Starck, Alexander Frick, Sebastian Gross, Ulrich Schurr, Friedrich S Eckstein, Sabina Hunziker, Rainer Schaefert. Originally published in Journal of Participatory Medicine (http://jopm.jmir.org), 06.07.2020. This is an open-access article distributed under the terms of the Creative Commons Attribution License (https://creativecommons.org/licenses/by/4.0/), which permits unrestricted use, distribution, and reproduction in any medium, provided the original work, first published in Journal of Participatory Medicine, is properly cited. The complete bibliographic information, a link to the original publication on http://jopm.jmir.org, as well as this copyright and license information must be included. 